INDUCTION OF LABOUR BY PUNCTURE OF THE MEMBRANES.

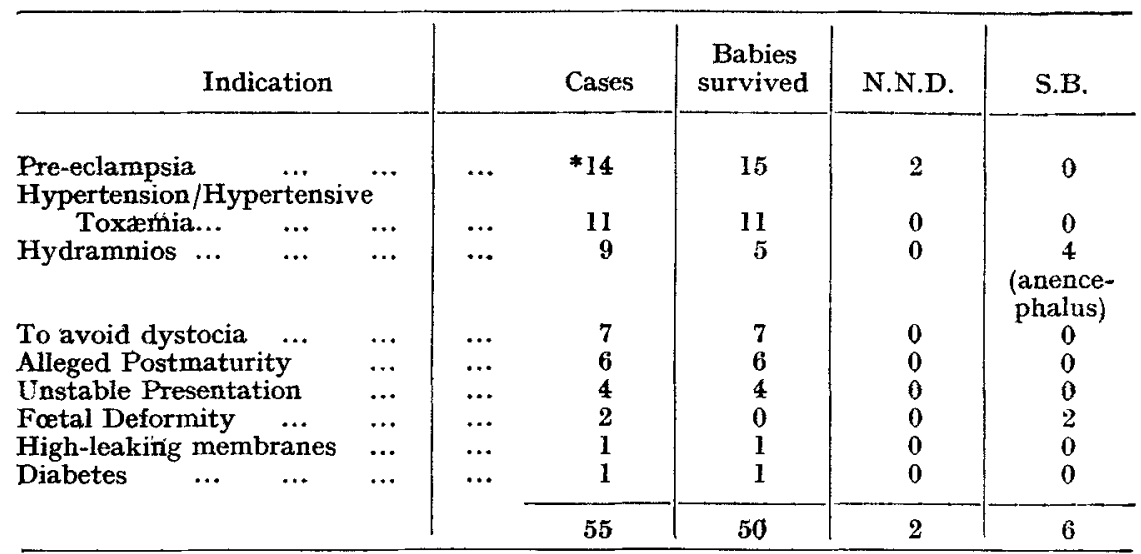

* 3 sets of twins

In addition, the membranes were punctured as a method of treatment or as a means of induction in $\mathbf{3 4}$ cases of antepartum hæmorrhage, including placenta prævia, and non-toxic and toxic accidental hæmorrhage (see special tables).

In 12 of the above 55 cases, the onset of labour was delayed for longer than 24 hours after puncture of the membranes. In point of fact, the induction - onset interval in 5 cases was 3 days ( 1 ), 4 to 5 days (2), 5 days (1) and 7 days (1). No fotal nor maternal complication was, however, attributable to this delay. The usual precautions against infection were adopted.

Breech presentation was not considered as a contra-indication to surgical induction.

In one case, shoulder and cord were found to be presenting after drainage of the liquor; living twins were delivered by Cæsarean Section (1097, Primary Section). In a second patient, a loop of cord come down, but the baby survived Section (1740, Primary Section).

The insertion of gum-elastic bougies was the method of induction in 7 primigravidæ, in whom puncture of the membranes was considered inadvisable because of the "unripe" state of the cervix. The indication for induction was toxæmia and all the babies survived. The insertion of bougies-onset of labour interval was 4 hours (2), 19 hours (1), 36 to 48 hours (3) and 72 hours (1). In Case 1036, bougie induction failed and Cæsarean Section was successfully performed.

\title{
LONG LABOUR.
}

Although it proved impossible to determine the exact duration of true labour in many cáses, especially in those patients already in labour on admission, it was considered that genuine labour contractions had been present for 30 hours or longer in 40 patients delivered within the Hospital in 1952. 